\title{
Maximizing neuroprotection: where do we stand?
}

\author{
This article was published in the following Dove Press journal: \\ Therapeutics and Clinical Risk Management \\ 5 April 2012 \\ Number of times this article has been viewed
}

\section{Damien P Kuffler \\ Institute of Neurobiology, University of Puerto Rico, San Juan, Puerto Rico}

Correspondence: Damien Kuffler Institute of Neurobiology, 20I Blvd del Valle, San Juan, Puerto Rico 0090 I

$\mathrm{Tel}+\mid \mathrm{I} 78772$ I I 235

Fax +I 787725 I289

Email dkuffler@hotmail.com
Abstract: Brain and spinal cord traumas include blunt and penetrating trauma, disease, and required surgery. Such traumas trigger events such as inflammation, infiltration of inflammatory and other cells, oxidative stress, acidification, excitotoxicity, ischemia, and the loss of calcium homeostasis, all of which cause neurotoxicity and neuron death. To prevent trauma-induced neurological deficits and death, each of the many neurotoxic events that occur in parallel or sequentially must be minimized or prevented. Although neuroprotective techniques have been developed that block single neurotoxic events, most provide only limited neuroprotection and are only applied singly. However, because many neurotoxicity triggers arise from common events, an approach for invoking more effective neuroprotection is to apply multiple neuroprotective methods simultaneously before the many neurotoxic triggers and cascades are initiated and become irreversible. This paper first discusses some triggers of neurotoxicity and neuroprotective mechanisms that block them, including hypothermia, alkalinization, and the administration of adenosine. It then examines how the simultaneous application of these techniques provides significantly greater neuroprotection than is provided by any technique alone. The paper also stresses the importance of determining whether the neuroprotection provided by these techniques can be further enhanced by combining them with additional techniques, such as the systemic administration of glucocorticoids. Finally, the paper stresses the absolute critical importance of applying these techniques within the "golden hour" following trauma, before the many neurotoxic events and cascades are manifest and before the neurotoxic cascades become irreversible.

Keywords: adenosine, hypothermia, alkalinization, glucocorticoids

\section{Introduction}

Brain and spinal cord traumas leading to neurotoxicity and neurological deficits include blunt and penetrating wounds, infections, and required surgeries that cause prolonged ischemia. Each of these insults triggers a complex cascade of secondary processes in the injured tissue, which results in a greatly enlarged secondary loss of tissue. ${ }^{1}$ Secondary causes of neurotoxicity include ischemia, ${ }^{2}$ the immediate result of disrupted blood flow, ${ }^{3}$ lipid peroxidation, ${ }^{4}$ oxidative stress, ${ }^{5}$ acidification, ${ }^{6}$ and inflammation. ${ }^{3}$ In addition, a multitude of cellular and gene events take place as a consequence of trauma, each of which has to be survived to provide neuroprotection.

Even small changes in the $\mathrm{pH}$ (predominantly decreases in $\mathrm{pH}$ ) result in dramatic changes in membrane properties that damage and kill neurons. ${ }^{7}$ Thus, acidification caused by ischemia leads to more extensive acidification due to the excessive release of excitatory amino acids (EAAs), ${ }^{8}$ which accumulate in the extracellular space, causing further extracellular acidification and inducing both necrotic and 
apoptotic neuron loss. ${ }^{8}$ Because certain neurons contain and release the EAAs glutamate and aspartate and have receptors for glutamate, the neurotoxic effect of the released glutamate is exacerbated because glutamate stimulates its own release in a positive feedback loop by its interaction with non-N-methyl-D-aspartic acid (NMDA) receptor subtypes. ${ }^{8}$ This in turn opens calcium ion channels, which allows a massive influx of extracellular calcium ${ }^{9}$ and causes a disruption in neurons' calcium homeostasis, ${ }^{10-12}$ leading to neuron death. Finally, calcium-induced calcium release and the further influx of calcium through voltage-gated calcium channels after glutamate-induced depolarization contribute to glutamate toxicity. Thus, a multitude of events and cascades are triggered, which lead to an ever-increasing neurotoxic environment and result in neurological losses and, eventually, death.

Trauma associated with even small physiologically relevant increases in temperature $\left(2^{\circ} \mathrm{C}\right)$ causes neuron death. ${ }^{13-15}$ The neurotoxicity is due to the release by microglia-like and astrocytic cells of monocyte chemotactic protein- 1 and the generation of reactive oxygen intermediates. ${ }^{14}$

Brain and spinal cord insults also trigger additional cascades of events that cause neurotoxicity by slightly different mechanisms, such as through an inflammatory response, ${ }^{16}$ in which neutrophils and some lymphocytes are recruited into the injured cat, rat, and mouse spinal cord. ${ }^{17}$ Activated macrophages/microglia are also recruited. ${ }^{18}$ In stroke, the resulting hypoxia triggers the production microglia to release interleukin-1 and tumor necrosis factor- $\alpha,{ }^{19}$ which kill neurons through an apoptotic mechanism. ${ }^{20}$ Within an injured area of the spinal cord, trauma also triggers the rapid expression of proinflammatory cytokines by endothelial cells and resident microglia. ${ }^{21}$ However, it remains unclear whether in addition to their beneficial functions neutrophils and microglia may also have harmful toxic effects for the surrounding healthy spinal cord tissue.

Inflammation is one of the early events triggered by trauma and includes the infiltration of the trauma site by monocytes that release molecules that are both neurotoxic and inhibit axon regeneration..$^{22}$ Therefore, currently, the most favored early intervention following central nervous system (CNS) injury is to antagonize or control the post injury inflammatory process using pharmaceutical agents. Among those holding promise in improving patient outcomes following brain and spinal cord injuries are broad-spectrum immunosuppressive drugs (eg, minocycline), growth factors (eg, erythropoietin), dual anti-inflammatory and antivasospasm drugs such as Rho and ROCK kinase inhibitors, and broad-spectrum anti-inflammatory drugs such as PDE4 inhibitors. ${ }^{23}$ However, the current gold standard of acute care for spinal cord injury is the administration of high doses of glucocorticoids such as methylprednisolone and pregabalin within 8 hours of injury. ${ }^{24}$ Their administration more than 8 hours post trauma may be without effect or may be detrimental to the outcome of the patient. ${ }^{23}$

New neurotoxic pathways and mechanisms by which to block them are constantly being discovered. For example, oxidative stress-induced neurotoxicity can be blocked with cinnamophilin, a potent antioxidant and free-radical scavenger with anti-inflammatory actions, which reduces acute ischemic brain damage when given up to 6 hours post ischemic insult. ${ }^{25}$ In addition, blocking microglial activation-induced neurotoxicity with urocortin, a member of the corticotropin-releasing hormone family of neuropeptides, regulates stress responses, thus providing neuroprotection. ${ }^{26}$

By knowing the identity of the many cellular and molecular triggers that cause trauma-induced neurotoxic cascades, different techniques can be applied one by one to block each of the triggers as it occurs. However, a simpler approach, and one that would provide even more enhanced neuroprotection, is to apply several broad-based neuroprotective techniques (hypothermia, alkalinization, administration of adenosine) simultaneously as soon as possible following trauma, when they can block the causes to the multiple neurotoxic cascades before they are triggered or at least before they become irreversible.

This review first examines specific causes and mechanisms of trauma-induced neurotoxicity and then looks at different techniques that block each trigger of neurotoxicity. It concludes by examining several methods that individually provide good neuroprotection but which when combined provide significantly greater neuroprotection by acting to prevent multiple neurotoxic triggers with overlapping mechanisms.

\section{Neurotoxicity}

\section{Ischemia}

Cerebral ischemia and head trauma lead to excitotoxicity and oxidative stress, which are major triggers of neurotoxicity. Although their neurotoxicity is initiated differently, most of their neurotoxic mechanisms are the same. Excitotoxic- and oxidative stress-induced neurotoxicity are linked because both are associated with neuron exposure to excess glutamate, which in turn causes a large increase in extracellular glutamate and intracellular calcium, acidosis, elevated potassium, activation of proteases, synthesis of nitric oxide (NO), 
and production of reactive oxygen species (ROS), which contribute to neurotoxicity. ${ }^{27}$

\section{Excitotoxicity}

Excitotoxicity involves two mechanisms related to the cytotoxic effects of glutamate: (1) intense stimulation of NMDA receptors, which can be generated by only 5 minutes of exposure to glutamate, causing death within $12-24$ hours $;{ }^{28}$ and

(2) non-NMDA receptor-mediated excitotoxicity, which takes more than 1 hour of exposure to induce a lethal stimulus.

Ischemia-induced excitotoxicity is neurotoxicity triggered by (1) excess release and extracellular accumulation of EAAs and excitotoxins such as glutamate and aspartate, which many neurons contain and release ${ }^{29}$ and for which they have receptors; ${ }^{30}$ (2) lipid peroxidation; ${ }^{4}$ and (3) trauma-induced inflammation. ${ }^{3}$ The extent of the increased extracellular glutamate concentration is related to the severity of the trauma, which in turn is directly related to the severity of the neurotoxicity and neuron death. ${ }^{31}$ Neuron exposure to an excessive concentration of extracellular EAAs leads to the excessive stimulation of their NMDA subtype of glutamate receptors and the development of a neurotoxic level of extracellular acidification ( $\mathrm{pH} 7.3-6.5$ ), with the extent of neuron death being related to the degree and duration of acidosis. ${ }^{32}$

Excessive glutamate release stimulates further glutamate release in a positive feedback loop by interacting with non-NMDA receptor subtypes ${ }^{32}$ and causing receptor activation. The acidification caused by the glutamate leads to the opening of receptor-coupled N-type voltagesensitive calcium channels, which allow further excessive entry of extracellular calcium into neurons. ${ }^{9}$ This elevated calcium then causes the loss of calcium homeostasis, which disrupts mitochondrial function and electron transport chain dysfunction and causes neuron death. ${ }^{33}$

Glutamate receptor antagonists such as the noncompetitive NMDA receptor antagonist dextrophan or the competitive antagonist 3-(2-carboxypiperazin-4-yl)propyl-1-phosphonic acid block a portion of the triggered neuronal toxicity and death. These data suggest that glutamate neurotoxicity and the subsequent degenerative processes are predominantly mediated by the activation of the NMDA subclass of glutamate receptors, occurring both directly during exposure to exogenous compounds and indirectly via the subsequent release of endogenous NMDA agonists. ${ }^{34}$

\section{Oxidative stress}

Oxidative stress is the result of the production of ROS such as superoxide anion, hydroxyl radical, and hydrogen peroxide
$\left(\mathrm{H}_{2} \mathrm{O}_{2}\right)$, which are produced during the process of neuronal death. ${ }^{35}$ Oxidative stress represents an imbalance between the production and manifestation of ROS and a biological system's ability to detoxify the reactive intermediates or to repair the resulting damage they cause.

Oxidative stress is exemplified by the actions of potassium cyanide, which initiates neurotoxicity as a rapidly acting mitochondrial poison that inhibits cellular respiration and energy metabolism (glycolysis), and also by causing extracellular acidification and the loss of calcium homeostasis. ${ }^{36}$ This leads to histotoxic hypoxia, a significant depletion of mitochondrial glutathione (diminished cellular antioxidant system), ${ }^{37}$ increased $\mathrm{H}_{2} \mathrm{O}_{2}$ generation, ${ }^{38}$ which is accompanied by lipid peroxidation, and generation of ROS and reactive nitrogen species, which damage all components of the cell, including proteins, lipids, and DNA. The effect of oxidative stress depends upon the magnitude of these changes, but cell death is initiated by apoptosis ${ }^{39}$ and necrosis. ${ }^{40}$

At excitotoxic concentrations, glutamate rapidly produces ROS by a process involving NMDA receptor activation and calcium entry through the NMDA receptors. ${ }^{41}$ This suggests that ROS production is an early event in glutamate-induced neuronal injury. This toxicity can be blocked by the mitochondrial proton ionophore carbonyl cyanide ptrifluo romethoxyphenylhydrazone, suggesting that ROS production also occurs due to calcium uptake into mitochondria ${ }^{41}$ and intracellular acidification. ${ }^{41}$ These studies suggest that mitochondria play a critical role in the production of ROS in association with glutamate excitotoxicity.

The application of antioxidants such as the 21-aminosteroid tirilizad can partially protect cultured neurons from NMDA receptor-mediated cell injury. ${ }^{42}$ Techniques that offer neuroprotection against excitotoxicity can be protective against oxidative stress and vice versa.

\section{Acidosis}

Acidosis is a universal tissue response to ischemia-induced oxidative stress and is caused by cyanide triggering a calciumdependent massive release of EAA transmitters. The acidosis induced by the extracellular accumulation of EAAs is linked to the worsening of cerebral infarction, in part from the restoration of oxidative metabolism following the oxidative stress and from neurotoxicity via EAA activation of NMDA receptors. ${ }^{43}$

\section{Increased intracellular calcium and loss of calcium homeostasis}

Cyanide causes a sustained increase in intracellular calcium, which leads to apoptosis ${ }^{44}$ with the extent of neuron death 
increasing with time of exposure. Cyanide-induced calcium increases are greater than those induced by glutamate because cyanide also induces the release of calcium from intracellular pools. ${ }^{45}$ However, cyanide neurotoxicity is not as extensive as that of glutamate, which indicates that a general elevation in cytoplasmic calcium does not necessarily predict neurodegeneration. ${ }^{45}$ The finding that cyanide induces a $32 \%$ increase in brain mitochondrial calcium levels supports the hypothesis that calcium plays an important role in cyanidemediated neurotoxicity, although the magnitude of the initial intracellular calcium concentration change does not predict the toxicity of an agonist on NMDA receptors. ${ }^{46,47}$

\section{Neuroprotection}

\section{Single techniques acting alone Hypothermia}

Hyperthermia leads to neurotoxicity, in part by causing neuroinflammation. ${ }^{14}$ Hypothermia provides neuroprotection by preventing the development of hyperthermia.

Clinically, whole-body and whole or localized brain hypothermia provide neuroprotection against infarct-induced oxidative stress. ${ }^{48}$ It also provides neuroprotection against compromised blood flow and reperfusion. ${ }^{49}$ Whole-body hypothermia provides only limited neuroprotection, probably because it requires interactions with additional environmental factors. Localized hypothermia $\left(32^{\circ} \mathrm{C}\right)$ provides good neuroprotection during periods of compromised cerebral blood flow and oxygen delivery. ${ }^{49}$ Different studies show that the temperature that provides best neuroprotection varies considerably from mild $\left(33^{\circ} \mathrm{C}-35^{\circ} \mathrm{C}\right)^{50}$ to moderate $\left(30^{\circ} \mathrm{C}-32^{\circ} \mathrm{C}\right),{ }^{51}$ severe $\left(27^{\circ} \mathrm{C}-29^{\circ} \mathrm{C}\right),{ }^{51}$ and extreme $\left(20^{\circ} \mathrm{C}\right) .{ }^{52}$

The first phase of neuroprotection by hypothermia is by reducing excitatory synaptic activity, which reduces the release and accumulation of excessive EAAs, reduces toxic extracellular acidification, ${ }^{53}$ and induces the expression of heat shock proteins. ${ }^{54}$ Hypothermia to $33^{\circ} \mathrm{C}$ reduces NMDA channel activation, ${ }^{50}$ thereby reducing NMDA receptormediated excitatory postsynaptic potential amplitude. ${ }^{55}$ Simultaneously, the activated channel open time is shortened, thereby reducing calcium influx and preventing the disruption of calcium homeostasis. The neuroprotection provided by hypothermia is enhanced when combined with the simultaneous infusion of NMDA receptor antagonists, ${ }^{56}$ and the neuroprotection provided by hypothermia is increased 23 -fold when combined with alkalinization. ${ }^{57}$

Mild hypothermia causes a 50-fold reduction in $\mathrm{H}_{2} \mathrm{O}_{2}$ production, which allows neurons to retain their normal cell morphology and viability. ${ }^{58}$ Whole-brain hypothermia (below $35^{\circ} \mathrm{C}$ ) impairs brain tissue oxygenation but provides neuroprotection by reducing the metabolic rate of neurons and thus their oxygen requirement ${ }^{59}$ while maintaining slightly better energy levels. ${ }^{60}$ Thus, the toxicity of oxidative stress is reduced by hypothermia by reducing adenosine triphosphate breakdown more than its synthesis, leading to improved neuron survival, which means that secondary failures in energy requirements are prevented. ${ }^{61}$ Hypothermia also causes ischemic neurons to significantly increase their expression of the antiapoptotic protein bcl-2. ${ }^{62}$ Thus, hypothermia lowers the risk of oxidative stress-induced cellular damage and programmed cell death by increasing the activity of glutathione-peroxidase due to the induced expression of the antiapoptotic protein bcl-2. ${ }^{62}$

Hypothermia during and after a period of oxygen-glucose deprivation and brief exposure to a high concentration of the NMDA or glutamate provide neuroprotection by reducing the release of glutamate and other EAAs into the extracellular space, thus reducing their excessive accumulation and the development of extracellular acidification, inhibiting excessive NMDA receptor activation, and shortening the NMDA receptor open channel time. ${ }^{50}$ These actions also minimize calcium influx through the open channel, thus preventing the disruption of calcium homeostasis. ${ }^{63}$

Hypothermia to $10^{\circ} \mathrm{C}$ improves the long-term survival of rats following hemorrhagic shock by decreasing tissue oxygen consumption and by altering the expression profiles of key genes, with an overall upregulation of prosurvival pathways and a downregulation of metabolic pathways. ${ }^{64}$

One concern about the clinical use of severe hypothermia (cooling to below $30^{\circ} \mathrm{C}$ ) is that it may be harmful to neurons, their circuits, or support cells. However, experiments on the spinal cord of large mammals (rabbits and pigs) show that reducing the temperature of the spinal cord to $4{ }^{\circ} \mathrm{C}$ for more than 30 minutes during complete ischemia does not cause the loss of neurons or their viable neuronal circuits, which would otherwise undergo massive loss if the spinal cord was maintained at higher temperatures. ${ }^{49}$

\section{Alkalinization}

Alkalinization provides neuroprotection against ischemiainduced acidification caused by the excessive release and accumulation of EAAs and excessive NMDA receptor activation. ${ }^{65,66}$ Alkalinization to $\mathrm{pH} 8.2$ protects adult rat $\mathrm{CNS}$ neurons against ischemic effects of infarct, ${ }^{67}$ and mouse neocortical neurons in primary culture from azide-induced chemical anoxia. ${ }^{68}$ Further, alkalinization of adult human dorsal root ganglion (DRG) neurons provides neuroprotection against 
glutamate and acidification, with neuroprotection increasing as $\mathrm{pH}$ increases from 7.6 to $9.3 .^{69}$

Oxidative stress-induced ischemia leads to rapid intracellular acidification, ${ }^{70}$ with the extent of neuron death being related to the degree and duration of extracellular acidosis. ${ }^{32}$ Extracellular $\mathrm{pH}$ changes result in similar intracellular $\mathrm{pH}$ shifts in DRG neurons. ${ }^{71}$ Oxidative stress-induced acidosis and death of cultured primary mouse neocortical neurons is prevented by alkalinization to $\mathrm{pH} 8.2 .{ }^{68}$ Alkalinization of adult rat CNS and adult human DRG neurons also provides neuroprotection against prolonged ischemia, ${ }^{6}$ with alkalinization to $\mathrm{pH} 8.2$ preventing the development of acidosis-induced neurotoxicity against azide-induced chemical anoxia. ${ }^{68}$ However, it is not known whether alkalinization acts by preventing EAA-induced acidosis or blocking the actions of glutamate. ${ }^{66}$

Alkalinization provides neuroprotection against increased intracellular calcium by changing the relative concentration of soluble extracellular calcium, which is $\mathrm{pH}$ dependent. Calcium requires a $\mathrm{pH}$ of $<6$ to enter solution, whereas at physiological pH 7.6, calcium solubility is $160 \mathrm{mg} / \mathrm{L}$ and increases to $6390 \mathrm{mg} / \mathrm{L}$ at $\mathrm{pH}$ 7.0. However, its solubility decreases 40 -fold to $10.1 \mathrm{gm} / \mathrm{L}$ at $\mathrm{pH} 8.4 .^{72}$ Thus, although decreasing intracellular $\mathrm{pH}$ leads to increased calcium solubility and neurotoxicity, alkalinization provides neuroprotection against cyanide toxicity by causing calcium precipitation into calcium bicarbonate, thus reducing the concentration of soluble extracellular calcium available to enter neurons. ${ }^{73}$ Similarly, removing intracellular calcium by chelation with 1,2-bis(o-aminophenoxy)ethane-N, $\mathrm{N} \mathrm{N}^{\prime}, \mathrm{N}^{\prime}$-tetraacetic acid partially reduces cyanide-induced neurotoxicity. ${ }^{74}$

NMDA receptors are $\mathrm{pH}$ sensitive with acidification resulting in (1) excessive calcium entry ${ }^{75}$ and neurotoxic increases in intracellular calcium, ${ }^{68}(2)$ the release of calcium from intracellular stores, ${ }^{76}$ and (3) the loss of calcium homeostasis. ${ }^{69}$ However, alkalinization from $\mathrm{pH} 7.6$ to $\mathrm{pH}$ 8.7 provides neuroprotection by reducing NMDA receptor activation and excess accumulation of neurotoxic intracellular calcium. ${ }^{75}$

Ischemia and cyanide induce the generation of neurotoxic NO free radicals. Free-radical formation can be prevented by intracellular alkalinization to $\mathrm{pH} 7.4$ during the initial 30 minutes of NO exposure. ${ }^{77}$ Therefore, extracellular alkalinization, which induces intracellular alkalinization, provides neuroprotection by reducing the production of oxygen free radicals.

\section{Adenosine}

Adenosine is a nucleoside rapidly formed in large amounts by neurons and glial cells during ischemia due to the intracellular breakdown of adenosine triphosphate. The adenosine is transported into the extracellular space, where it provides endogenous neuroprotection by counteracting the generation of the neurotoxic increases in the extracellular calcium concentration. ${ }^{78}$ Administration of the adenosine A2A agonists during prolonged spinal cord ischemia exerts neuroprotection, ${ }^{79}$ and this neuroprotection is increased when combined with hypothermia. ${ }^{80}$

Adenosine provides neuroprotection by suppressing the neurotoxic gamma-aminobutyric acid (GABA)-activated current in a majority of the neurons (77\%). ${ }^{81}$ Similarly, regional hypothermia together with the simultaneous infusion of an NMDA receptor antagonist enhances the neuroprotection provided by hypothermia. ${ }^{56}$ When hypothermia and alkalinization are applied simultaneously, they provide greater neuroprotection to ischemic adult rat DRG neurons than either one alone. ${ }^{82}$

Neuroprotection by adenosine agonists results from ischemia inducing the upregulation of adenosine A2A receptors (A2A-R). ${ }^{79}$ If adenosine A2A-R induction is blocked, perfusion with adenosine A2A agonists does not provide neuroprotection, reduce reperfusion-associated inflammation, reduce paralysis, or reduce neuronal apoptosis. ${ }^{79}$ Thus, A2A-R agonists exert their neuroprotective effects by activating the induced neuronal A2A-R upregulated during spinal cord reperfusion. ${ }^{79}$ However, the earlier the perfusion with the A2A receptor agonist is initiated after the start of ischemia, the greater the neuroprotection that is provided. ${ }^{83}$

Adenosine A1 receptor agonists or inhibitors of cellular reuptake and inactivation of adenosine provide neuroprotection against glutamate-induced excitotoxicity by blocking calcium influx mediated by the NMDA receptor and preventing the loss of intracellular calcium homeostasis. ${ }^{84} \mathrm{~A} 1$ adenosine receptor activation suppresses neural activity by a predominantly presynaptic action, ${ }^{85}$ probably by directly stabilizing the neuronal membrane potential by increasing the conductance for potassium and chloride ions. This blocks glutamate induction of an uncontrolled membrane depolarization via ion channel-linked glutamate receptors of the NMDA type. ${ }^{86}$ This blocks voltage-sensitive potassium currents, increases NMDA receptor-mediated calcium influx, and impairs glutamate uptake by astrocytes.$^{87}$ Adenosine appears to provide neuroprotection by suppressing the neurotoxic GABA-activated current in a majority of the neurons $(77 \%) .{ }^{81}$

\section{Neurotrophic factors}

The neurotrophic factors nerve growth factor ${ }^{88,89}$ and brainderived neurotrophic factor ${ }^{90}$ facilitate brain tissue repair 
following experimental traumatic brain injury such as ischemia by stimulating increases in neuronal metabolism, cell size, and process outgrowth. ${ }^{91}$

\section{Neuropeptides}

A number of neuropeptides provide neuroprotection. Cortistatin, a neuropeptide with endocrine activities in humans, provides neuroprotection against bacterial infection. ${ }^{92}$ Neuropeptide Y provides dopaminergic cell neuroprotection against 6-hydroxydopamine-induced toxicity in vitro and in animal models of Parkinson's disease. ${ }^{93}$ Neuronal damage caused by excess activation of NMDA is blocked by the neuropeptide apelin via its activation of G-protein-coupled receptors by modulating neuronal prosurvival pathways and/or NMDA receptor signaling. ${ }^{94}$ The neuropeptide galanin, which is upregulated in the brain of patients with Alzheimer's disease, provides neuroprotection against amyloid- $\beta$ toxicity and other excitotoxic injuries, by activating the second galanin receptor subtype. ${ }^{95}$

\section{Plasticity}

Biological organisms evolved to be able to respond to stress with plasticity that promotes neuroprotection and cell survival. One example of plasticity to stress is the plasticity of astrocytes, which following injury can produce glial scar tissue that inhibits axon regeneration but can also release factors that at the same injury site provide neuroprotection and support axonal regeneration. ${ }^{96}$ Another example is the amyloid precursor protein (APP), which, under stress, such as Alzheimer's disease, is not cleaved, leading to its triggering neurodegeneration. However, under physiological conditions, APP is processed by the nonamyloidogenic pathway, leading to secreted N-terminal APP fragment, which provides neuroprotection, synaptic plasticity, neurite outgrowth, and synaptogenesis ${ }^{97}$ Finally, aging is associated with low-grade neuroinflammation, including microglia activation, which appears to contribute to deficits in neural plasticity and cognitive function. However, mice subjected to stress in the form of exercise by wheel running show a decrease in microglia activation but an increase in microglia-expressing insulin-like growth factor-1, which provides neuroprotection. ${ }^{98}$

\section{Precondition}

Preconditioning neurons to various compounds causes a reprogramming of mitochondrial biology to those noxious stress stimuli, which leads to both increased mitochondrial and neuronal tolerance against neurodegenerative events. ${ }^{99,100}$ Hypoxic preconditioning provides neuroprotection against subsequent hypoxia, in part by inhibiting neuronal apoptosis. ${ }^{101}$ The neuroprotection is caused by the preconditioning hypoxia, leading to an increased production of the delta opioids receptor (DOR) and the DOR ligand L-ENK. DOR activation following hypoxic preconditioning is responsible for providing enhanced neuroprotection against subsequent ischemia. ${ }^{101}$ Hypoxia-induced neuroprotection is also associated with hypoxia-inducible factor-1- $\alpha$, which regulates astrocyte iron metabolism and transport, and by hypoxia preconditioning changing the expression of iron metabolism proteins. ${ }^{102}$

\section{Erythropoietin}

Beyond their hematopoietic functions, blood progenitor cells release the growth factors erythropoietin, granulocyte colony-stimulating factor, and thrombopoietin, which provide neuroprotection while also promoting neuronal growth. ${ }^{103-105}$

\section{Stem cells}

Implantation of stem cells provides neuroprotection. Following an optic nerve crush, many axotomized retinal ganglion cells die due to a lack of target-derived neurotrophic factors. But the delivery of bone-marrow mononuclear cells provides neuroprotection and increases both retinal ganglion cell survival and axon outgrowth. ${ }^{106}$ Similarly, mesenchymal stem cells transplanted into the rat brain reduce ischemia-induced brain damage in rats by inducing a marked increase in the synthesis of neurotrophic factors such as vascular endothelial growth factor, epidermal growth factor, and basic fibroblast growth factor in the host brain. ${ }^{107}$ Another example is the implantation of human umbilical cord blood cells, which provide neuroprotection against neurological deficits in both in vitro and in vivo models of ischemic brain injuries, potentially by reducing inflammation and trophic actions and enhancing angiogenesis. ${ }^{108}$

\section{Cell lines}

The transplantation of HMO6, a human microglial cell line, provides neuroprotection following ischemia by reducing gliosis and neuroinflammation, and by enhancing the production of neurotrophic factors from endogenous and transplanted cells. ${ }^{109}$

\section{Multiple techniques acting simultaneously}

As discussed previously, hypothermia, alkalinization, and adenosine each applied singly provides neuroprotection against the consequences of trauma. However, additional evidence shows that the simultaneous application of these 
techniques enhances the neuroprotection they provide in both clinical and animal model studies.

\section{Hypothermia plus alkalinization}

The neuroprotection against prolonged ischemia provided by hypothermia $\left(20^{\circ} \mathrm{C}\right)$ and alkalinization $(\mathrm{pH} 9.3)$ combined is by approximately three-fold greater than when they are applied singly. ${ }^{82}$

\section{Hypothermia and NMDA receptor antagonists}

Regional hypothermia together with the simultaneous infusion of an NMDA receptor antagonist enhances the neuroprotection provided by hypothermia. ${ }^{56}$

\section{Hypothermia and adenosine $\mathrm{A} 2 \mathrm{~A}$ receptor agonists}

The neuroprotection provided by localized hypothermia against 45 minutes of ischemia is increased by the simultaneous local infusion with adenosine.$^{80}$ However, neuroprotection is even greater when the local perfusion of the ischemic spinal cord with hypothermic saline is combined with the systemic infusion of an adenosine $\mathrm{A} 2 \mathrm{~A}$ receptor agonist. ${ }^{110}$

\section{Conclusion}

Traumas trigger neurotoxicity by different mechanisms, among which are the massive release of EAAs, acidification, excessive activation of NMDA receptors, the massive intracellular increase in calcium, loss of calcium homeostasis, oxidative stress, and lipid peroxidation, each causing neurotoxicity by separate mechanisms. Although different techniques singly provide neuroprotection against each of these neurotoxic triggers, no one method provides neuroprotection against all the other neurotoxic events that occur simultaneously as well as sequentially. Strong evidence suggests that hypothermia, alkalinization, and adenosine provide greater neuroprotection than that produced by any alternative neuroprotective techniques. However, the simultaneous application of these three techniques provides significantly greater neuroprotection than that of any one alone. Further evidence suggests that their neuroprotection can be even further enhanced when they are combined with additional methods, such as administration of glucocorticoids. Finally, it must be stressed that to be optimally effective these neuroprotective techniques must be applied within the "golden hour" of a trauma, before the different neurotoxic cascades are triggered and become irreversible.

\section{Disclosure}

The author reports no conflicts of interest in this work.

\section{References}

1. Schwab ME, Bartholdi D. Degeneration and regeneration of axons in the lesioned spinal cord. Physiol Rev. 1996;76(2):319-370.

2. Choi DW. Cerebral hypoxia: some new approaches and unanswered questions. J Neurosci. 1990;10(8):2493-2501.

3. Schnell L, Fearn S, Klassen H, Schwab ME, Perry VH. Acute inflammatory responses to mechanical lesions in the CNS: differences between brain and spinal cord. Eur J Neurosci. 1999;11(10):3648-3658.

4. Cuzzocrea S, McDonald MC, Mazzon E, et al. Effects of tempol, a membrane-permeable radical scavenger, in a gerbil model of brain injury. Brain Research. 2000;875(1-2):96-106.

5. Flamm ES, Demopoulos HB, Seligman ML, Poser RG, Ransohoff J. Free radicals in cerebral ischemia. Stroke. 1978;9(5):445-447.

6. Reyes O, Sosa I, Kuffler DP. Neuroprotection of adult human neurons against ischemia by hypothermia and alkalinization. $P$ R Health Sci J. 2006;25(1):43-50.

7. Amorim P, Cottrell JE, Kass IS. Effect of small changes in temperature on CA1 pyramidal cells from rat hippocampal slices during hypoxia: implications about the mechanism of hypothermic protection against neuronal damage. Brain Res. 1999;844(1-2):143-149.

8. Sucher NJ, Lipton SA, Dreyer EB. Molecular basis of glutamate toxicity in retinal ganglion cells. Vision Res. 1997;37(24):3483-3493.

9. Frandsen A, Schousboe A. Dantrolene prevents glutamate cytotoxicity and $\mathrm{Ca} 2+$ release from intracellular stores in cultured cerebral cortical neurons. J Neurochem. 1991;56(3):1075-1078.

10. Cebers G, Cebere A, Liljequist S. Metabolic inhibition potentiates AMPA-induced $\mathrm{Ca} 2+$ fluxes and neurotoxicity in rat cerebellar granule cells. Brain Res. 1998;779(1-2):194-204.

11. Leist M, Nicotera P. Calcium and neuronal death. Rev Physiol Biochem Pharmacol. 1998;132:79-125.

12. Wang C, Nguyen HN, Maguire JL, Perry DC. Role of intracellular calcium stores in cell death from oxygen-glucose deprivation in a neuronal cell line. J Cereb Blood Flow Metab. 2002;22(2):206-214.

13. Demierre N, Wyler D, Zollinger U, Bolliger S, Plattner T. Elevated body core temperature in medico-legal investigation of violent death. Am J Forensic Med Pathol. 2009;30(2):155-158.

14. Bahniwal M, Villanueva EB, Klegeris A. Moderate increase in temperature may exacerbate neuroinflammatory processes in the brain: human cell culture studies. J Neuroimmunol. 2011;233(1-2):65-72.

15. Kiyatkin EA. Brain temperature homeostasis: physiological fluctuations and pathological shifts. Front Biosci. 2010;15:73-92.

16. Dusart I, Schwab ME. Secondary cell death and the inflammatory reaction after dorsal hemisection of the rat spinal cord. Eur J Neurosci. 1994;6(5):712-724.

17. Schnell L, Schneider R, Berman MA, Perry VH, Schwab ME. Lymphocyte recruitment following spinal cord injury in mice is altered by prior viral exposure. Eur J Neurosci. 1997;9(5):1000-1007.

18. Blight AR. Macrophages and inflammatory damage in spinal cord injury. J Neurotrauma. 1992;9 Suppl 1:S83-S91.

19. Liu T, Clark RK, McDonnell PC, et al. Tumor necrosis factor-alpha expression in ischemic neurons. Stroke. 1994;25(7):1481-1488.

20. Kaushal V, Schlichter LC. Mechanisms of microglia-mediated neurotoxicity in a new model of the stroke penumbra. J Neurosci. 2008;28(9):2221-2230.

21. Bartholdi D, Schwab ME. Expression of pro-inflammatory cytokine and chemokine mRNA upon experimental spinal cord injury in mouse: an in situ hybridization study. Eur J Neurosci. 1997;9(7):1422-1438.

22. Fitch MT, Silver J. CNS injury, glial scars, and inflammation: inhibitory extracellular matrices and regeneration failure. Exp Neurol. 2008;209(2):294-301.

23. Pearse D, Jarnagin K. Abating progressive tissue injury and preserving function after CNS trauma: the role of inflammation modulatory therapies. Curr Opin Investig Drugs. 2010;11(11):1207-1210.

24. Zhang Q, Huang C, Tang T, Shi Q, Yang H. Comparative neuroprotective effects of methylprednisolone and rosiglitazone, a peroxisome proliferator-activated receptor-gamma following spinal cord injury. Neurosciences (Riyadh). 2011;16(1):46-52. 
25. Chen T-Y, Tai S-H, Lee E-J, et al. Cinnamophilin offers prolonged neuroprotection against gray and white matter damage and improves functional and electrophysiological outcomes after transient focal cerebral ischemia. Crit Care Med. 2011;39:1130-1137.

26. Wang MJ, Lin SZ, Kuo JS, Huang HY, Tzeng SF. Urocortin modulates inflammatory response and neurotoxicity induced by microglial activation. J Immunol. 2007;179:6204-6214.

27. Choi DW. Methods for antagonizing glutamate neurotoxicity. Cerebrovasc Brain Metab Rev. 1990;2(2):105-147.

28. Zipfel GJ, Babcock DJ, Lee JM, Choi DW. Neuronal apoptosis after CNS injury: the roles of glutamate and calcium. $J$ Neurotrauma. 2000;17(10):857-869

29. Garthwaite J, Garthwaite G. Mechanisms of excitatory amino acid neurotoxicity in rat brain slices. Adv Exp Med Biol. 1990;268:505-518.

30. Lee CJ, Engelman HS, MacDermott AB. Activation of kainate receptors on rat sensory neurons evokes action potential firing and may modulate transmitter release. Ann $N$ Y Acad Sci. 1999;868:546-549.

31. Choi DW. Possible mechanisms limiting N-methyl-D-aspartate receptor overactivation and the therapeutic efficacy of N-methyl-D-aspartate antagonists. Stroke. 1990;21(11 Suppl):III20-III22.

32. Ding D, Moskowitz SI, Li R, et al. Acidosis induces necrosis and apoptosis of cultured hippocampal neurons. Exp Neurol. 2000;162(1):1-12.

33. Benveniste $H$. The excitotoxin hypothesis in relation to cerebral ischemia. Cerebrovasc Brain Metab Rev. 1991;3(3):213-245.

34. Choi DW, Koh JY, Peters S. Pharmacology of glutamate neurotoxicity in cortical cell culture: attenuation by NMDA antagonists. J Neurosci. 1988;8(1):185-196.

35. Coyle JT, Puttfarcken P. Oxidative stress, glutamate, and neurodegenerative disorders. Science. 1993;262(5134):689-695.

36. Bhattacharya R, Lakshmana Rao PV. Pharmacological interventions of cyanide-induced cytotoxicity and DNA damage in isolated rat thymocytes and their protective efficacy in vivo. Toxicol Lett. 2001;119(1):59-70.

37. Schafer FQ, Buettner GR. Redox environment of the cell as viewed through the redox state of the glutathione disulfide/glutathione couple. Free Radic Biol Med. 2001;30(11):1191-1212.

38. Abdollahi H, Harris LJ, Zhang P, et al. The role of hypoxia in stem cell differentiation and therapeutics. J Surg Res. 2011;165(1): 112-117.

39. Li L, Prabhakaran K, Shou Y, Borowitz JL, Isom GE. Oxidative stress and cyclooxygenase-2 induction mediate cyanide-induced apoptosis of cortical cells. Toxicol Appl Pharmacol. 2002;185(1): 55-63.

40. Lennon SV, Martin SJ, Cotter TG. Dose-dependent induction of apoptosis in human tumour cell lines by widely diverging stimuli. Cell Prolif. 1991;24(2):203-214.

41. Reynolds IJ, Hastings TG. Glutamate induces the production of reactive oxygen species in cultured forebrain neurons following NMDA receptor activation. J Neurosci. 1995;15(5 Pt 1): 3318-3327.

42. Monyer H, Seeburg PH. Constituents involved in glutamate receptor signaling. Hippocampus. 1993;3:125-129.

43. Kanthasamy AG, Maduh EU, Peoples RW, Borowitz JL, Isom GE. Calcium mediation of cyanide-induced catecholamine release: implications for neurotoxicity. Toxicol Appl Pharmacol. 1991;110(2):275-282.

44. Hirata H, Machado LS, Okuno CS, Brasolin A, Lopes GS, Smaili SS. Apoptotic effect of ethanol is potentiated by caffeine-induced calcium release in rat astrocytes. Neurosci Lett. 2006;393(2-3): 136-140.

45. Dubinsky JM, Rothman SM. Intracellular calcium concentrations during "chemical hypoxia" and excitotoxic neuronal injury. J Neurosci. 1991;11(8):2545-2551.
46. Choi DW. Glutamate neurotoxicity and diseases of the nervous system. Neuron. 1988;1(8):623-634.

47. Rajdev S, Reynolds IJ. Glutamate-induced intracellular calcium changes and neurotoxicity in cortical neurons in vitro: effect of chemical ischemia. Neuroscience. 1994;62(3):667-679.

48. Debillon T, Daoud P, Durand P, et al. Whole-body cooling after perinatal asphyxia: a pilot study in term neonates. Dev Med Child Neurol. 2003;45(1):17-23.

49. Parrino PE, Kron IL, Ross SD, et al. Spinal cord protection during aortic cross-clamping using retrograde venous perfusion. Ann Thorac Surg. 1999;67(6):1589-1594; discussion 1594-1585.

50. Mori K, Maeda T, Shiraishi Y, Kawai Y. Effects of hypothermia on blood flow and neural activity in rabbit spinal cord during postischemic reperfusion. Jpn J Physiol. 2001;51(1):71-79.

51. Mori K, Maeda M, Miyazaki M, Iwase H. Effects of mild (33 degrees C) and moderate (29 degrees $\mathrm{C}$ ) hypothermia on cerebral blood flow and metabolism, lactate, and extracellular glutamate in experimental head injury. Neurol Res. 1998;20(8):719-726.

52. Sosa IJ, Reyes O, Inserni J, Kuffler DP. Isolation and long-term survival of adult human sensory neurons in vitro. Neurosurgery. 1998;42(3):681685; discussion 685-686.

53. Nishi H, Nakatsuka T, Takeda D, et al. Hypothermia suppresses excitatory synaptic transmission and neuronal death induced by experimental ischemia in spinal ventral horn neurons. Spine (Phila Pa 1976). 2007;32(25):E741-E747.

54. Yenari MA. Heat shock proteins and neuroprotection. Adv Exp Med Biol. 2002;513:281-299.

55. Musleh W, Alvarez S, Baudry M, Alkana RL. Effects of ethanol and temperature on NMDA receptor function in different mouse genotypes. Alcohol Clin Exp Res. 1996;20(7):1299-1304.

56. Lucas JH, Emery DG, Wang G, Rosenberg-Schaffer LJ, Jordan RS, Gross GW. In vitro investigations of the effects of nonfreezing low temperatures on lesioned and uninjured mammalian spinal neurons. J Neurotrauma. 1994;11(1):35-61.

57. Kuffler DP. Combinatorial techniques for enhancing neuroprotection: hypothermia and alkalinization. Ann N Y Acad Sci. 2010;1199: 164-174.

58. Zitta K, Meybohm P, Bein B, et al. Hypoxia-induced cell damage is reduced by mild hypothermia and postconditioning with catalase in-vitro: application of an enzyme based oxygen deficiency system. Eur J Pharmacol. 2010;628(1-3):11-18.

59. Gupta AK, Al-Rawi PG, Hutchinson PJ, Kirkpatrick PJ. Effect of hypothermia on brain tissue oxygenation in patients with severe head injury. Br J Anaesth. 2002;88(2):188-192.

60. Robertson CL, Scafidi S, McKenna MC, Fiskum G. Mitochondrial mechanisms of cell death and neuroprotection in pediatric ischemic and traumatic brain injury. Exp Neurol. 2009;218(2):371-380.

61. Erecinska M, Thoresen M, Silver IA. Effects of hypothermia on energy metabolism in Mammalian central nervous system. J Cereb Blood Flow Metab. 2003;23(5):513-530.

62. Slikker W 3rd, Desai VG, Duhart H, Feuers R, Imam SZ. Hypothermia enhances bcl-2 expression and protects against oxidative stress-induced cell death in Chinese hamster ovary cells. Free Radic Biol Med. 2001;31(3):405-411.

63. Kuffler DP. Neuroprotection by hypothermia plus alkalinization of dorsal root ganglia neurons through ischemia. Ann N Y Acad Sci. 2010;1199:158-163.

64. Alam HB, Hashmi S, Finkelstein RA, et al. Alterations in gene expression after induction of profound hypothermia for the treatment of lethal hemorrhage. J Trauma. 2010;68(5):1084-1098.

65. Skaper SD, Facci L, Kee WJ, Strijbos PJ. Potentiation by histamine of synaptically mediated excitotoxicity in cultured hippocampal neurones: a possible role for mast cells. J Neurochem. 2001;76(1):47-55.

66. Ishikawa T, Marsala M. Hypothermia prevents biphasic glutamate release and corresponding neuronal degeneration after transient spinal cord ischemia in the rat. Cell Mol Neurobiol. 1999;19(2):199-208. 
67. Dietrich WD, Busto R, Alonso O, Globus MY, Ginsberg MD Intraischemic but not postischemic brain hypothermia protects chronically following global forebrain ischemia in rats. $J$ Cereb Blood Flow Metab. 1993;13(4):541-549.

68. Jorgensen NK, Petersen SF, Damgaard I, Schousboe A, Hoffmann EK. Increases in $[\mathrm{Ca} 2+]$ i and changes in intracellular $\mathrm{pH}$ during chemical anoxia in mouse neocortical neurons in primary culture. $J$ Neurosci Res. 1999;56(4):358-370.

69. Reyes O, Sosa I, Kuffler DP. Neuroprotection of adult human neurons against ischemia by hypothermia and alkalinization. $P$ R Health Sci $J$. 2006;25(1):43-50.

70. Henrich M, Buckler KJ. Effects of anoxia and aglycemia on cytosolic calcium regulation in rat sensory neurons. J Neurophysiol. 2008;100(1):456-473.

71. Chesler M. pH regulation in the vertebrate central nervous system: microelectrode studies in the brain stem of the lamprey. Can J Physiol Pharmacol. 1987;65(5):986-993.

72. Goss SL, Lemons KA, Kerstetter JE, Bogner RH. Determination of calcium salt solubility with changes in $\mathrm{pH}$ and $\mathrm{P}(\mathrm{CO}(2))$, simulating varying gastrointestinal environments. $J$ Pharm Pharmacol. 2007;59(11):1485-1492.

73. Maduh EU, Borowitz JL, Isom GE. Cyanide-induced alteration of cytosolic $\mathrm{pH}$ : involvement of cellular hydrogen ion handling processes. Toxicol Appl Pharmacol. 1990;106(2):201-208.

74. Yang CW, Borowitz JL, Gunasekar PG, Isom GE. Cyanide-stimulated inositol 1,4,5-trisphosphate formation: an intracellular neurotoxic signaling cascade. J Biochem Toxicol. 1996;11(5):251-256.

75. Gemignani A, Paudice P, Longordo F, Raiteri M. External pH changes affect NMDA-evoked and spontaneous release of cholecystokinin, somatostatin and noradrenaline from rat cerebrocortical nerve endings. Neurochem Int. 2004;45(5):677-685.

76. Chen YH, Wu ML, Fu WM. Regulation of presynaptic NMDA responses by external and intracellular $\mathrm{pH}$ changes at developing neuromuscular synapses. J Neurosci. 1998;18(8):2982-2990.

77. Vincent AM, TenBroeke M, Maiese K. Neuronal intracellular pH directly mediates nitric oxide-induced programmed cell death. J Neurobiol. 1999;40(2):171-184.

78. Schubert P, Ogata T, Marchini C, Ferroni S, Rudolphi K. Protective mechanisms of adenosine in neurons and glial cells. Ann NY Acad Sci. 1997;825:1-10.

79. Cassada DC, Tribble CG, Long SM, et al. Adenosine A2A agonist reduces paralysis after spinal cord ischemia: correlation with A2A receptor expression on motor neurons. Ann Thorac Surg. 2002;74(3):846849; discussion 849-850.

80. Ross SD, Kern JA, Gangemi JJ, et al. Hypothermic retrograde venous perfusion with adenosine cools the spinal cord and reduces the risk of paraplegia after thoracic aortic clamping. J Thorac Cardiovasc Surg. 2000;119(3):588-595.

81. Hu HZ, Li ZW. Modulation by adenosine of GABA-activated current in rat dorsal root ganglion neurons. $J$ Physiol. 1997;501(Pt 1):67-75.

82. Cruz O, Kuffler DP. Neuroprotection of adult rat dorsal root ganglion neurons by combined hypothermia and alkalinization against prolonged ischemia. Neuroscience. 2005;132(1):115-122.

83. Reece TB, Tribble CG, Okonkwo DO, et al. Early adenosine receptor activation ameliorates spinal cord reperfusion injury. $J$ Cardiovasc Med (Hagerstown). 2008;9(4):363-367.

84. Wardas J. Neuroprotective role of adenosine in the CNS. Pol J Pharmacol. 2002;54(4):313-326.

85. Stone TW. Purines and neuroprotection. Adv Exp Med Biol. 2002;513:249-280.

86. Calabresi P, Picconi B, Saulle E, Centonze D, Hainsworth AH, Bernardi G. Is pharmacological neuroprotection dependent on reduced glutamate release? Stroke. 2000;31(3):766-772; discussion 773.

87. Stone TW, Ceruti S, Abbracchio MP. Adenosine receptors and neurological disease: neuroprotection and neurodegeneration. Handb Exp Pharmacol. 2009;193:535-587.
88. Yang JP, Liu HJ, Yang H, Feng PY. Therapeutic time window for the neuroprotective effects of NGF when administered after focal cerebral ischemia. Neurol Sci. 2011;32(3):433-441.

89. Mao QQ, Zhong XM, Qiu FM, Li ZY, Huang Z. Protective effects of paeoniflorin against corticosterone-induced neurotoxicity in PC12 cells. Phytother Res. 2011. Epub Dec 1.

90. De Santi L, Polimeni G, Cuzzocrea S, et al. Neuroinflammation and neuroprotection: an update on (future) neurotrophin-related strategies in multiple sclerosis treatment. Curr Med Chem. 2011;18(12):1775-1784.

91. Skaper SD. Peptide mimetics of neurotrophins and their receptors. Curr Pharm Des. 2011;17(25):2704-2718.

92. Chiu CT, Wen LL, Pao HP, Wang JY. Cortistatin is induced in brain tissue and exerts neuroprotection in a rat model of bacterial meningoencephalitis. J Infect Dis. 2011;204(10):1563-1572.

93. Decressac M, Pain S, Chabeauti PY, et al. Neuroprotection by neuropeptide $\mathrm{Y}$ in cell and animal models of Parkinson's disease. Neurobiol Aging. 2011. Epub Aug 2.

94. Cook DR, Gleichman AJ, Cross SA, et al. NMDA receptor modulation by the neuropeptide apelin: implications for excitotoxic injury. J Neurochem. 2011;118(6):1113-1123.

95. Elliott-Hunt CR, Holmes FE, Hartley DM, Perez S, Mufson EJ, Wynick D. Endogenous galanin protects mouse hippocampal neurons against amyloid toxicity in vitro via activation of galanin receptor-2. J Alzheimers Dis. 2011;25(3):455-462.

96. Haas C, Neuhuber B, Yamagami T, Rao M, Fischer I. Phenotypic analysis of astrocytes derived from glial restricted precursors and their impact on axon regeneration. Exp Neurol. 2011;233(2): $717-732$

97. Kogel D, Deller T, Behl C. Roles of amyloid precursor protein family members in neuroprotection, stress signaling and aging. Exp Brain Res. 2011. Epub Nov 16.

98. Kohman RA, Deyoung EK, Bhattacharya TK, Peterson LN, Rhodes JS. Wheel running attenuates microglia proliferation and increases expression of a proneurogenic phenotype in the hippocampus of aged mice. Brain Behav Immun. 2011. Epub Oct 25.

99. Correia SC, Cardoso S, Santos RX, et al. New insights into the mechanisms of mitochondrial preconditioning-triggered neuroprotection. Curr Pharm Des. 2011;17(31):3381-3389.

100. Onishi A, Miyamae M, Kaneda K, Kotani J, Figueredo VM. Direct evidence for inhibition of mitochondrial permeability transition pore opening by sevoflurane preconditioning in cardiomyocytes: comparison with cyclosporine A. Eur J Pharmacol. 2012;675(1-3): $40-46$.

101. Gao CJ, Niu L, Ren PC, et al. Hypoxic preconditioning attenuates global cerebral ischemic injury following asphyxial cardiac arrest through regulation of delta opioid receptor system. Neuroscience. 2011;202:352-362

102. Yang L, Fan M, Du F, et al. The increased iron transport rate induced by hypoxic preconditioning in astrocytes. Biochim Biophys Acta. 2012. Epub Dec 16.

103. Diederich K, Schabitz WR, Minnerup J. Seeing old friends from a different angle: novel properties of hematopoietic growth factors in the healthy and diseased brain. Hippocampus. 2010. Epub Dec 6.

104. Fan X, Kavelaars A, Heijnen CJ, Groenendaal F, van Bel F. Pharmacological neuroprotection after perinatal hypoxic-ischemic brain injury. Curr Neuropharmacol. 2010;8(4):324-334.

105. Rees S, Harding R, Walker D. The biological basis of injury and neuroprotection in the fetal and neonatal brain. Int J Dev Neurosci. 2011;29(6):551-563

106. Zaverucha-do-Valle C, Gubert F, Bargas-Rega M, et al. Bone marrow mononuclear cells increase retinal ganglion cell survival and axon regeneration in the adult rat. Cell Transplant. 2011;20(3): 391-406. 
107. Wakabayashi K, Nagai A, Sheikh AM, et al. Transplantation of human mesenchymal stem cells promotes functional improvement and increased expression of neurotrophic factors in a rat focal cerebral ischemia model. J Neurosci Res. 2010;88(5):1017-1025.

108. Arien-Zakay H, Lecht S, Nagler A, Lazarovici P. Neuroprotection by human umbilical cord bloodderived progenitors in ischemic brain injuries. Arch Ital Biol. 2011;149(2):233-245.
109. Narantuya D, Nagai A, Sheikh AM, et al. Human microglia transplanted in rat focal ischemia brain induce neuroprotection and behavioral improvement. PLoS One. 2010;5(7):e11746.

110. Reece TB, Okonkwo DO, Ellman PI, et al. Comparison of systemic and retrograde delivery of adenosine $\mathrm{A} 2 \mathrm{~A}$ agonist for attenuation of spinal cord injury after thoracic aortic cross-clamping. Ann Thorac Surg. 2006;81(3):902-909.

\section{Publish your work in this journal}

Therapeutics and Clinical Risk Management is an international, peerreviewed journal of clinical therapeutics and risk management, focusing on concise rapid reporting of clinical studies in all therapeutic areas, outcomes, safety, and programs for the effective, safe, and sustained use of medicines. This journal is indexed on PubMed Central, CAS,
EMBase, Scopus and the Elsevier Bibliographic databases. The manuscript management system is completely online and includes a very quick and fair peer-review system, which is all easy to use. Visit http://www.dovepress.com/testimonials.php to read real quotes from published authors.

Submit your manuscript here: http://www.dovepress.com/therapeutics-and-clinical-risk-management-journal 